\title{
Modeling the impact of rotifer contamination on microalgal production in open pond, photobioreactor and thin layer cultivation systems
}

\author{
Bert Deruyck $^{\mathrm{a}, *}$, Kim Hue Thi Nguyen ${ }^{\mathrm{a}, \mathrm{b}}$, Ellen Decaestecker ${ }^{\mathrm{a}}$, Koenraad Muylaert ${ }^{\mathrm{a}}$ \\ ${ }^{\text {a }}$ KU Leuven Kulak, Laboratory Aquatic Biology, E. Sabbelaan 53, 8500 Kortrijk, Belgium \\ ${ }^{\mathrm{b}}$ Department of Biology, College of Natural Sciences, Can Tho University, Vietnam
}

\section{A R T I C L E I N F O}

\section{Keywords:}

Biological contamination

Brachionus calyciflorus

Chlorella vulgaris

Large-scale microalgae cultivation

Predator-prey dynamics modeling

\begin{abstract}
A B S T R A C T
Contamination of microalgal cultures by rotifers is known to cause large losses in productivity. The factors that control population dynamics of rotifers in microalgal cultures were studied in controlled contamination experiments in laboratory cultures. These experiments revealed that rotifer growth rates increase with microalgae biomass at low rotifer population densities and declines with rotifer biomass as the rotifer population approaches a carrying capacity. Experimental results were used to construct a model that describes the impact of rotifer contamination on three types of large-scale microalgal cultures. The results of this model indicate that rotifer contamination causes a complete loss in productivity in open pond and closed photobioreactor cultivation systems. In contrast, losses in productivity are limited in thin layer cascade reactors because the rotifer population cannot achieve a sufficiently high population density to cause a crash of the culture. These results suggest that different cultivation systems respond differently to rotifer contamination.
\end{abstract}

\section{Introduction}

Microalgae are a promising source of biomass for the production of food, feed, fuel and bulk chemicals [1,2]. Large-scale microalgae cultivation systems, however, often suffer unforeseen losses in productivity due to contamination of cultures by parasites and predators of microalgae [3,4]. Predators that feed on microalgae such as rotifers and ciliates are a particularly important threat because these microorganisms can decimate microalgal biomass in a matter of days (e.g. $[5,6])$. There is a lack of research on the types of microalgal predators that invade large-scale cultures and their impact on the productivity of these cultures [8].

A common type of predator that invades microalgal cultures are rotifers $[7,9,10]$. Rotifers are microscopic multicellular organisms that vary in size from 50 to $500 \mu \mathrm{m}$ and live in freshwater as well as marine environments. They are the smallest and fastest-growing multicellular organisms with high evolutionary potential to adapt to changing conditions $[11,12]$. Rotifers possess a ciliated structure, the corona, which is used for swimming as well as for filtering food particles from the water. Food particles are grinded in the mastax by a muscular pharynx containing tiny calcified jaws (trophi) [13]. Rotifers generally reproduce asexually by producing non-fertilized eggs (parthenogenesis) and will turn to sexual reproduction under adverse conditions. The outcome of sexual reproduction is a diapausing embryo in the egg stage

\section{[14].}

Ample information is available about population dynamics of rotifers from studies in natural ecosystems (e.g. $[15,16])$ and from laboratory studies using rotifers as a model organisms for ecological or evolutionary research (e.g. $[12,17,18])$. Yet, there is little information about the factors that control the population dynamics of rotifers in intensive microalgal cultures, where microalgal biomass concentration is much higher than in natural ecosystems. This information is important to assess the impact of rotifer contamination on large-scale production systems of microalgae [19]. As with any predator, the population dynamics of rotifers are strongly influenced by food availability and, hence, microalgal biomass concentration [20]. Different microalgae cultivation systems differ strongly in the operational microalgal biomass concentration, ranging from $<0.5 \mathrm{gL}^{-1}$ in open ponds to several $\mathrm{g} \mathrm{L}^{-1}$ in photobioreactors and $>10 \mathrm{~g} \mathrm{~L}^{-1}$ in thin layer cascade systems [21]. Because microalgal biomass concentration influences rotifer population dynamics, we can expect that these systems will respond differently to rotifer contamination. In addition to food availability, rotifer population dynamics may also be regulated by the population size of the rotifers. Rotifer population growth rates tend to decline as the rotifer population reaches a given carrying capacity (e.g. [22]). This carrying capacity of the rotifer population will set an upper limit to the rate of microalgal biomass consumption by rotifers.

Until today, reactive measures were the main focus of research on

\footnotetext{
* Corresponding author.

E-mail address: bert.deruyck@kuleuven-kortrijk.be (B. Deruyck).
} 
combating rotifers in microalgal cultivation systems [4]. Many solutions have been proposed in the literature, ranging from chemical (e.g. rotenone [23], free $\mathrm{NH}_{3}$ [24], toosendanin [25], $\mathrm{CO}_{2}$ asphyxiation [26]), mechanical (e.g. filtration [27]), physical (e.g. hydrodynamic cavitation [28]), to biological methods (e.g. introduction of zooplanktivorous species [5]). Preventative measures, that prevent or lower the risk of contamination and complete culture loss upon rotifer contamination are much less documented [29]. The only well-established successful preventative measure is the creation of extreme culture conditions whereby the growth of the target microalgae is favorited over possible entering contaminates [27]. However, different types of large-scale microalgal cultivation systems might also differ in their resilience to contamination by predators and as such serve as a preventative measure. To date, there is a vigorous debate in the scientific community about the advantages and disadvantages of different types of large-scale microalgal cultivation systems (e.g. [30,31]). An underappreciated argument in this debate is the resilience of these systems to contamination by predators [8]. The aim of this study was to investigate how different cultivation systems might respond to contamination of the culture by rotifers. Carrying out controlled contamination experiments in large-scale cultivation systems is however complicated because such experiments would result in large losses in biomass output of the system. Also the need for thorough decontamination of the system after completing the experiment forms a major drawback of experimenting with large-scale systems. Therefore, we developed a model describing rotifer population dynamics in microalgal cultures. The necessary parameters to model rotifer population dynamics were obtained from controlled small-scale contamination experiments in laboratory conditions over a range of microalgal biomass concentrations. This model was then integrated with a model describing microalgae productivity in three types of cultivation systems (open raceway pond, closed flat-panel photobioreactor and thin layer cascade) to simulate the impact of rotifer contamination on different large-scale microalgal production systems.

\section{Material and methods}

\subsection{Cultivation of Chlorella vulgaris and Brachionus calyciflorus}

The rotifer Brachionus calyciflorus and the microalgae Chlorella vulgaris were used in controlled contamination experiments as a model system to study the impact of rotifer contamination on microalgal cultures. The Chlorella vulgaris strain SAG 211-11 B was maintained in semi-continuous cultures in $2 \mathrm{~L}$ glass bottles. The cultivation medium was based on Wright's Cryptophyte (WC) medium and contained $85.0 \mathrm{mg} \mathrm{L}^{-1} \quad \mathrm{NaNO}_{3}, \quad 37.0 \mathrm{mg} \mathrm{L}^{-1} \quad \mathrm{MgSO}_{4} .7 \mathrm{H}_{2} \mathrm{O}, \quad 36.8 \mathrm{mg} \mathrm{L}^{-1}$ $\mathrm{CaCl}_{2} .2 \mathrm{H}_{2} \mathrm{O}, 12.6 \mathrm{mg} \mathrm{L}^{-1} \mathrm{NaHCO}, 38.7 \mathrm{mg} \mathrm{L}^{-1} \mathrm{~K}_{2} \mathrm{HPO}_{4}$, trace metals and vitamins [32]. Cultures were buffered using Tris buffer $(4.13 \mathrm{mM})$ and $\mathrm{pH}$ was adjusted to $8-8.1$ by addition of $0.5 \mathrm{M} \mathrm{HCl}$. Daylight fluorescent tubes were used for irradiation, providing a light intensity of $60 \mu \mathrm{E} \mathrm{m}^{-2} \mathrm{~s}^{-1}$ at one side of the bottle within a $16 \mathrm{~h}-8 \mathrm{~h}$ light-dark cycle. Cultures were sparged with $0.2 \mu \mathrm{m}$ filtered air to supply $\mathrm{CO}_{2}$ and remove oxygen and magnetic stirring was applied to ensure continuous mixing. Temperature was kept constant at $22 \pm 1{ }^{\circ} \mathrm{C}$. Exponential phase Chlorella cultures were used in the experiments.

The rotifer Brachionus calyciflorus was isolated from a freshwater pond nearby the KU Leuven campus in Kortrijk, Belgium $\left(50.8080^{\circ} \mathrm{N}\right.$, $3.2925^{\circ} \mathrm{E}$ ). Rotifers were grown in batch mode in $0.5 \mathrm{~L}$ bottles and were fed with Chlorella cells from an exponential phase culture. The same culture medium and light and temperature conditions were used as for the cultivation of Chlorella. Food concentrations in the Brachionus cultures varied between 0.1 and $0.35 \mathrm{~g} \mathrm{~L}^{-1}$. Every 4 to 5 days, part of the rotifer culture was transferred to fresh medium and supplied with fresh food, with a starting density of 0.1 to 1 rotifers $\mathrm{mL}^{-1}$. Rotifers were maintained in the lab for several months before experimentation.

\subsection{Experimental set-up}

To evaluate how the microalgal biomass concentration influences the growth and predation rate of the rotifers, a series of controlled contamination experiments were carried out. A total of 29 microalgal cultures were set up with initial microalgal biomass concentrations ranging over two orders of magnitude (from 0.04 to $4.4 \mathrm{~g} \mathrm{~L}^{-1}$ ). These cultures were prepared in $300 \mathrm{~mL}$ glass jars with a culture volume of $100 \mathrm{~mL}$. For biomass concentrations above $0.5 \mathrm{~g} \mathrm{~L}^{-1}$, the biomass was concentrated by centrifugation $(3500 \mathrm{~g}, 12 \mathrm{~min})$. Additional nutrients were added to the treatments to avoid nutrient limitation of the microalgae during the course of the experiment. The microalgal cultures were contaminated with rotifers at an initial density of 5 rotifers $\mathrm{mL}^{-1}$. Uncontaminated cultures without rotifers served as a control. All treatments were stirred and aerated. The experiments were monitored daily during 6 or 7 days. Microalgal biomass was monitored by measuring the absorbance at $750 \mathrm{~nm}$ (OD750). OD750 was calibrated against dry weight (DW) biomass concentration (determined gravimetrically by filtering a known volume of culture on pre-weighed GF/F filters dried at $105^{\circ} \mathrm{C}$ ). OD750 was linearly related to DW (DW $\left.\left(\mathrm{mg} \mathrm{L}^{-1}\right)=353 \cdot \mathrm{OD} 750, \mathrm{R}^{2}=0.99, \mathrm{n}=22\right)$. DW was also related to cell abundance ( 1 cell $=3.6 \pm 1.5 \mathrm{pg}$ (average \pm standard deviation), $\mathrm{n}=22$ ). Rotifer abundance was determined in $2 \mathrm{~mL}$ subsamples using a Sedgewick Rafter counting chamber and a stereomicroscope (Olympus SZX10). Rotifer abundance was either determined immediately on live samples, or within one week in subsamples fixed with formaldehyde (4\%). Abundance (rotifers $\mathrm{mL}^{-1}$ ) was converted to dry weight biomass $\left(\mathrm{mg} \mathrm{L}^{-1}\right)$ assuming an average mass of one rotifer individual of $200 \mathrm{ng}$ (e.g. [33,34]). No distinction was made between eggbearing and non-egg-bearing females.

In these experiments, we noted that the rotifer population growth rate declined when the rotifer population size reached a carrying capacity. To investigate which factors controlled this decline in population growth rate, an additional experiment was carried out during which environmental conditions as well as the ratio of live/dead rotifers were monitored in detail in a contaminated culture. Also changes in the number of egg-bearing females, non-egg-bearing females and the average number of eggs per egg-bearing female were followed. Therefore, a control culture and a rotifer contaminated culture were monitored during 7 days (initial microalgal biomass concentration was $1600 \mathrm{mg} \mathrm{L}^{-1}$ and initial rotifer abundance was 10 rotifers $\mathrm{mL}^{-1}$ ). Daily changes in microalgal biomass concentrations and rotifer abundance were monitored daily as described above. Average number of eggs carried by an egg-bearing female were determined by counting a minimum of 20 randomly picked egg-bearing females. Dissolved oxygen (DO; HQ40D, HACH, USA) concentration and $\mathrm{pH}$ were monitored daily. In the contaminated culture, DO was monitored at high resolution ( $5 \mathrm{~min}$ interval).

\subsection{Calculation of rotifer and microalgal growth rates}

Growth rates of microalgae and rotifers were calculated for each 1 day time interval in each experimental treatment. To accurately estimate rotifer growth rates, only 1 day intervals were included where rotifer abundance was $\geq 25$ ind mL $\mathrm{m}^{-1}$ at the start and the end of the interval. Exponential growth rates $r\left(\right.$ day $^{-1}$ ) of rotifers were calculated as:

$r=\ln \left(\frac{R_{1}}{R_{0}}\right)$

In which $R_{O}$ and $R_{1}$ correspond to rotifer biomass concentration at the start and the end of the 1 day interval. Microalgal exponential growth rates $\mu\left(\right.$ day $\left.^{-1}\right)$ were calculated as: 
$\mu=\ln \left(\frac{A_{1}}{A_{0}}\right)$

In which $A_{O}$ and $A_{1}$ correspond to microalgal biomass concentration at the start and the end of the 1 day interval. The average concentration of microalgal biomass $\left(A_{\text {avg }}\right)$ over each 1 day time interval was calculated as:

$A_{\text {avg }}=\frac{A_{1}-A_{0}}{\ln \left(A_{1}\right)-\ln \left(A_{0}\right)}$

The average concentration of rotifer biomass over each 1 day time interval $\left(R_{\text {avg }}\right)$ was calculated using the same formula.

\subsection{Modeling of growth and predation rates of rotifers in the laboratory experiments}

A dynamic predator-prey model was developed to simulate the population dynamics of rotifers and microalgae in the laboratory experiments. This model was based on the principles of the classical Lotka-Volterra model and consists of two coupled differential equations:

$\frac{d A}{d t}=\mu \cdot A-g \cdot R \cdot A$

$\frac{d R}{d t}=g \cdot \gamma \cdot R \cdot A-m \cdot R$

Eq. (4) describes the change in microalgal biomass concentration (A) over time, which is a function of the microalgal growth rate $(\mu)$ and rotifer grazing rate $(g)$. Eq. (5) describes changes in rotifer biomass concentration $(R)$ over time and is a function of rotifer grazing rate $(g)$, rotifer growth efficiency $\gamma$ (the ratio of rotifer biomass produced over microalgal biomass consumed) and rotifer mortality rate $(\mathrm{m})$.

Data from the experimental control treatments (without rotifers) were used to derive the parameters for a model of the growth of microalgae. In these treatments, microalgal growth $(d A / d t)$ is only a function of microalgal biomass concentration $A$ and the microalgal growth rate $\mu$ :

$\frac{d A}{d t}=\mu \bullet A$

The growth rate $\mu$ is a function of the areal biomass concentration (the product of the volumetric biomass concentration $A$ and culture depth $z$ ) and the daily areal microalgal biomass production $P$, which is in turn a function of the microalgal biomass concentration.

$\mu=\ln \left(\frac{A \cdot z+P}{A \cdot z}\right)$

To estimate the depth-integrated areal biomass production $P$, we used the equation provided by Huisman and Weissing 1994 [35], which is a numerical solution for the integral of microalgal biomass production over the depth $z$ of the culture:

$P=\frac{\mu_{\max }}{k} \cdot \ln \left(\frac{H+I_{i n}}{H+I_{i n} \cdot e^{-k \cdot A \cdot z}}\right)$

This equation assumes that primary production is only regulated by light $\left(I_{\text {in }}\right)$, that irradiance in the culture is only absorbed by microalgae and that the photosynthesis-irradiance curve follows a Monod response [35]. In this formula, the areal biomass production $P$ is a function of the microalgal biomass concentration $A$ and a series of parameters which are constant in the model: the culture depth $(z, 0.027 \mathrm{~m})$, the maximum growth rate of the microalgae $\left(\mu_{\mathrm{max}}\right)$, the biomass-specific absorption coefficient $\left(k\right.$, in $\left.\mathrm{m}^{2} \mathrm{~g}^{-1}\right)$, the light intensity at which microalgal productivity is half the maximal productivity $(H)$ and the light intensity at the surface of the reactor $\left(I_{i n}\right)$. The light intensity at the surface of the reactor was measured using a PAR sensor $\left(I_{\text {in }}=83 \mu \mathrm{E} \mathrm{m}^{-2} \mathrm{~s}^{-1}\right)$. The parameter $k$ was measured spectrophotometrically by integrating the biomass-specific absorption over the PAR range (400 to $700 \mathrm{~nm}$ ) ( $k=0.8$ ) [36]. The parameter $H$ was estimated from a light response curve measured using a PAM (pulse amplitude modulated) fluorometer [37] (AP100, Photon Systems Instruments, Czech Republic). To measure the light response curve, an exponential phase Chlorella culture was dark adapted and the light response curve was measured using a standard protocol. This light response curve represents the apparent electron transport rate (estimated from the effective quantum yield of photosystem II and the light intensity) as a function of the light intensity. Parameter $H$ was estimated by fitting a Monod curve to the light response curve $\left(H=120 \mu \mathrm{E} \mathrm{m}^{-2} \mathrm{~s}^{-1}\right.$; Supplementary Information Fig. $\mathrm{S} 1)$. Finally, the maximum growth rate $\left(\mu_{\max }\right)$ was estimated by fitting the observed microalgal growth rates in the control treatments of the experiments to the modeled growth rates using non-linear least squares regression $\left(\mu \max =2.7 \mathrm{day}^{-1}\right.$; Supplementary Information Fig. S2). The modeled growth rates fitted well with the observed growth rates in the experiments $\left(n=73, F_{4,68}=82.8 ; p<0.0001 ; R^{2}=0.84\right)$ indicating that the model was able to accurately predict phytoplankton growth rates in the experiments.

The growth efficiency $(\gamma)$ of rotifers feeding on Chlorella was estimated from the ratio of produced rotifer biomass over consumed microalgal biomass. This ratio $\gamma$ was calculated for each 1 day time interval in all experiments. The quantity of consumed microalgal biomass was calculated from the observed microalgal biomass concentration at the end of the 1 day interval and the expected microalgal biomass concentration in the absence of rotifer predation. The expected biomass concentration at the end of the 1 day interval was estimated from the biomass concentration at start of the 1 day interval and the biomass production during the 1 day interval estimated using Eq. (8). The average growth efficiency $\gamma$ was $21 \%$ (standard deviation $12 \%$, $\mathrm{n}=60$ ).

Data from the experimental treatments containing rotifers were used to derive the parameters to model the growth of rotifers. The rotifer grazing rate $g$ corresponds to the growth rate $r$ divided by the growth efficiency $\gamma$. Analysis of rotifer growth rates in the experiments indicated that $r$ increased with microalgal biomass concentration $A$ at low microalgal biomass concentration and saturated at a maximum growth rate at high microalgal biomass concentration. This corresponds to a Holling type II functional response, which can be modeled using a quadratic hyperbola. In addition, rotifer growth rates declined linearly with increasing rotifer biomass concentration $(R)$. Thus, rotifer growth rate $r$ could be estimated from microalgal biomass concentration $(A)$ and rotifer biomass concentration $(R)$ as:

$r=r_{\max } \cdot \frac{A}{K_{r}+A} \cdot\left(1-\frac{R}{C_{r}}\right)$

in which $r_{\max }$ is the maximum growth rate of the rotifers, $K_{r}$ is the microalgal biomass concentration where $r$ is half of $r_{\max }$ and $C_{r}$ is the carrying capacity of rotifers, or the rotifer biomass concentration above which $r$ becomes negative. Average mortality rate of rotifers was assumed to be constant at 0.15 day $^{-1}$ (e.g. [12]). As a result, Eq. (5) can be rewritten as:

$\frac{d R}{d t}=\frac{r_{\max }}{\gamma} \cdot \frac{A}{K_{r}+A} \cdot\left(1-\frac{R}{C_{r}}\right)-m \cdot R$

Parameters values were derived by curve fitting using Sigmaplot version 11.0. The 'deSolve' package in $\mathrm{R}$ (version 3.4.1) was used to model growth of rotifers and microalgae in the 29 different laboratory experiments [38]. Modeled biomass concentrations of microalgae and rotifers were compared to observations in the experiments.

\subsection{Modeling the impact of rotifer contamination in large-scale cultures}

The model that was developed to simulate rotifer contamination in the lab-scale experiments was adapted to simulate the impact of rotifer 

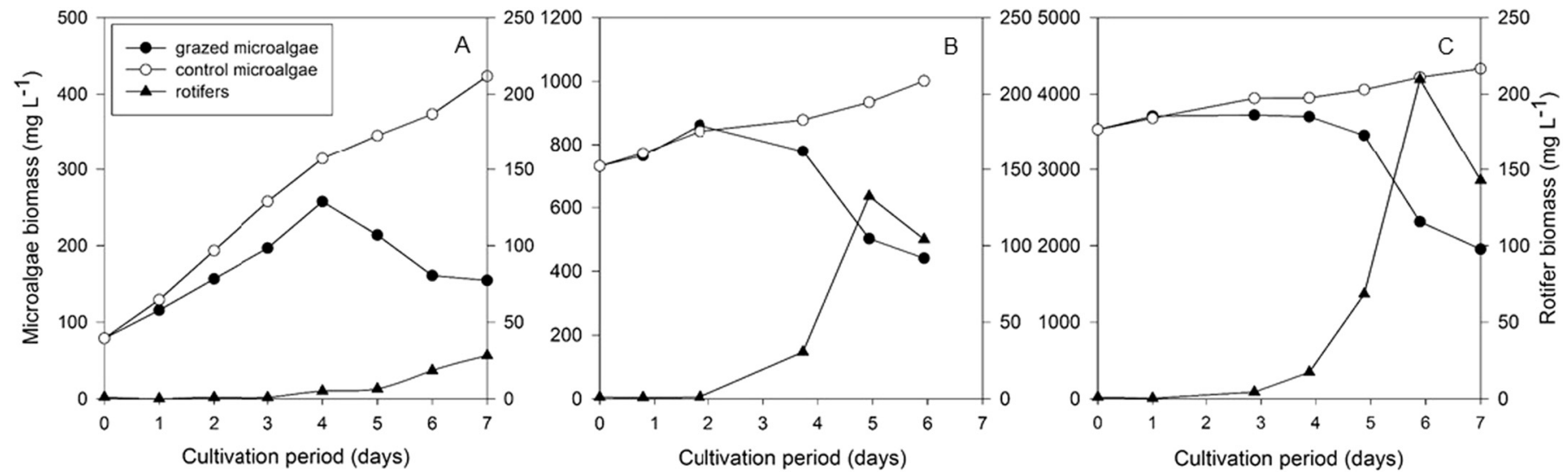

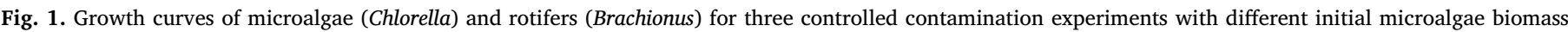

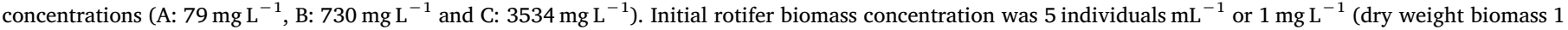
rotifer $=200 \mathrm{ng})$. Microalgae biomass $\left(A, \mathrm{mg} \mathrm{L}^{-1}\right)$ is indicated on the left y-axis, rotifer biomass $\left(R, \mathrm{mg} \mathrm{L}^{-1}\right)$ is indicated on the right $\mathrm{y}$-axis.

contamination in large-scale microalgal cultures. Because large-scale cultures are typically operated in continuous mode, a loss factor $(d)$ was added to account for the daily harvesting of the biomass.

$\frac{d A}{d t}=\mu \cdot A-g \cdot R \cdot A-d \cdot A$

$\frac{d R}{d t}=g \cdot \gamma \cdot R \cdot A-(m+d) \cdot R$

The impact of rotifer contamination was simulated for three different types of cultivation systems: an open raceway pond, a horizontal flat-panel photobioreactor and an open thin layer cascade. These systems differ primarily with respect to the depth of the culture $(z)$ and the operational microalgal biomass concentration. The culture depth $z$ was set at $30 \mathrm{~cm}$ for the open raceway ponds, $5 \mathrm{~cm}$ for the horizontal flatpanel photobioreactor and $0.6 \mathrm{~cm}$ for the thin layer cascade. The operational biomass concentration was $0.5 \mathrm{~g} \mathrm{~L}^{-1}$ for the open raceway ponds, $4 \mathrm{~g} \mathrm{~L}^{-1}$ for the horizontal flat-panel photobioreactor and $30 \mathrm{~g} \mathrm{~L}^{-1}$ for the thin layer cascade. The dilution rate was set at the level of the growth rate that is achieved by the microalgae at the operational microalgal biomass concentration and ranged from 0.15 day $^{-1}$ for the open raceway pond, $0.11 \mathrm{day}^{-1}$ for the photobioreactor and 0.13 day $^{-1}$ for the thin layer cascade system. As a result, the microalgal biomass concentration is constant when no rotifer contamination is included in the model. Other parameters were the same as for the model used to describe rotifer contamination in laboratory cultures, except for a higher light intensity at the surface of the culture $\left(1000 \mu \mathrm{E} \mathrm{m}^{-2} \mathrm{~s}^{-1}\right)$ and a lower specific light extinction coefficient $\left(k=0.25 \mathrm{~m}^{2} \mathrm{~g}^{-1}\right)$. The specific light extinction coefficient is lower in outdoor cultures than in laboratory cultures as a result of a higher light intensity, which results in photo-acclimation and a decrease in the pigment concentration in the biomass [39]. The specific light extinction coefficient used here represents a realistic value for Chlorella sp. grown in large scale cultures exposed to natural sunlight [40].

For the rotifer model, the parameters were the same as in the model based on the laboratory experiments. The initial rotifer abundance in the model was set at either 1 individual $\mathrm{L}^{-1}$ or 1 individual $\mathrm{m}^{-3}$. An abundance of 1 individual $\mathrm{L}^{-1}$ corresponds to the rotifer abundance that occurs in a typical municipal water supply [41] and might realistically be expected when tap water is used without further decontamination to make up the microalgal culture medium. An abundance of 1 individual $\mathrm{m}^{-3}$ corresponds to a situation where this water is further treated to remove $99.9 \%$ of the rotifer population. The 'deSolve' package in R (version 3.4.1) was used to model growth of rotifers and microalgae in the three different cultivation systems [38]. Rotifer and microalgae dynamics were simulated for a period of 90 days and changes in biomass were calculated over 70 min intervals. To keep the model simple, light intensity was assumed to be constant over $24 \mathrm{~h}$.

Predator-prey models based on the Lotka-Volterra typically display regular cycles of increases and decreases in prey and predator populations. These cycles are regular when prey and predator populations are only regulated by predation, but these cycles can be dampened when prey and/or predator populations are influenced by intraspecific competition in addition to predation [42]. Intraspecific competition is present in the microalgal model in the form of light limitation of microalgal growth rates at high microalgal biomass concentration, and also in the rotifer model when rotifer biomass approaches its carrying capacity. The trajectories of prey and predator population can be visualized as orbits in a phase space determined by rotifer and microalgal biomass concentration. The trajectories can be related to their respective zero isoclines, which correspond to lines in the phase space where rotifer biomass is constant $\left(\frac{d R}{d t}=0\right)$ or microalgal biomass is constant $\left(\frac{d A}{d t}=0\right)$. These isoclines were calculated by numerically solving the differential equations using the Runge-Kutta method in R.

A summary of all variables and constants that describe the presented predator-prey model are listed in Supplementary Information Table S1.

\section{Results and discussion}

\subsection{Controlled contamination experiments at laboratory scale}

A total of 29 controlled contamination experiments were carried out in which the initial rotifer abundance was fixed at 5 rotifers $\mathrm{mL}^{-1}$ but the initial microalgal biomass concentration ranged from 40 to $4400 \mathrm{mg} \mathrm{L}^{-1}$. A selection of three representative experiments is shown in Fig. 1 (results of all 29 experiments are shown in Supplementary Information Fig. S4). In control cultures that were not contaminated with rotifers the microalgal biomass concentration increased over time. This increase was stronger when initial microalgal biomass concentration was low than when it was high, which can be explained by lightlimitation at high microalgal biomass concentrations. In cultures that were contaminated with rotifers, rotifer biomass increased over time. This increase was slower in treatments in which initial microalgal biomass concentration was low than when initial biomass was high. The microalgal biomass concentration decreased as rotifer biomass increased. When the rotifer biomass was very high, above $200 \mathrm{mg} \mathrm{L}^{-1}$, a decline in the rotifer biomass occurred, even when microalgal biomass concentration was high, suggesting that rotifer growth rates are constrained at high rotifer population densities.

Exponential growth rates of the rotifer population were calculated for each one-day time interval in all experiments, resulting in a total of 82 data points. Rotifer growth rates 

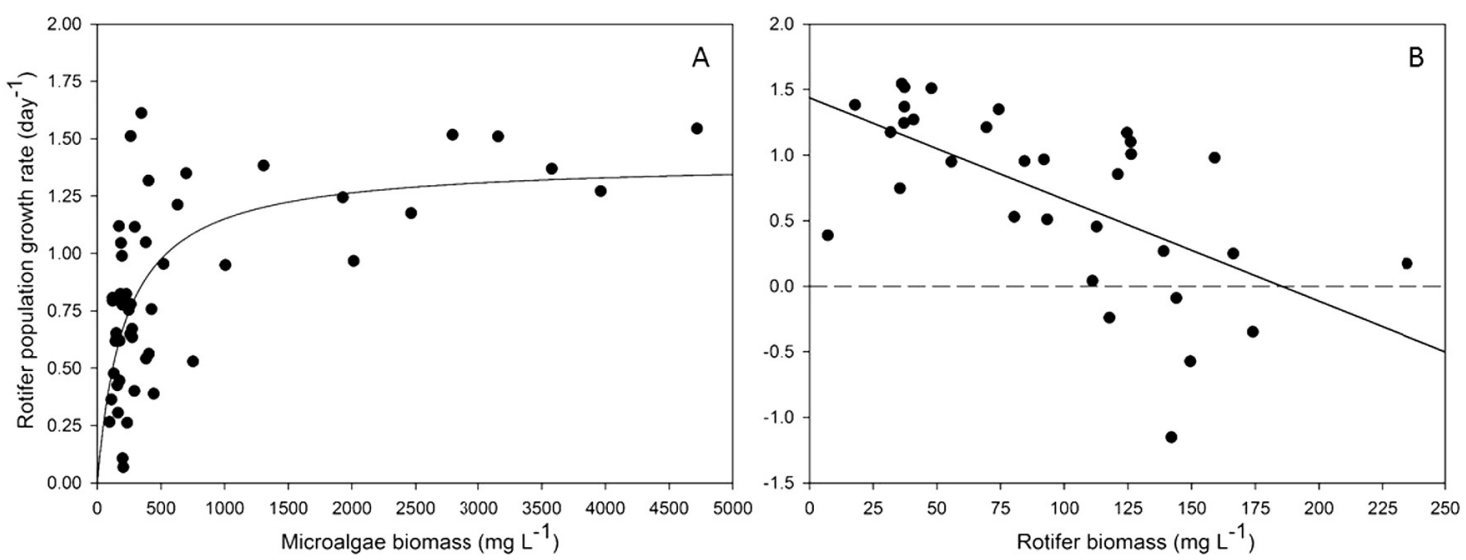

Fig. 2. (A) Rotifer population growth rate $\left(r\right.$, day $\left.{ }^{-1}\right)$ as a function of microalgae biomass $\left(A, \mathrm{mg} \mathrm{L}^{-1}\right)$. The solid line represents the fitted rectangular hyperbola $\left(r=\frac{r_{\max } \cdot A}{K_{r}+A}\right.$ ), with maximal growth rate $r_{\max }=1.4$ and $K_{r}$ is the microalgae biomass at which half the maximal growth rate occurs $\left(\mathrm{n}=50, \mathrm{R}^{2}=0.42, \mathrm{p}<0.0001\right)$. (B) Rotifer population growth rate as a function of rotifer biomass $\left(R, \mathrm{mg} \mathrm{L}^{-1}\right)$. The solid line represents the fitted linear regression line $\left(\mathrm{n}=32, \mathrm{R}^{2}=0.39\right.$, $\mathrm{p}=0.0001)$.

were related to the average microalgal and rotifer biomass concentration over the corresponding time interval (Fig. 2). When the rotifer biomass concentration was low (below ca. $60 \mathrm{mg} \mathrm{L}^{-1}$, or 300 rotifers $\mathrm{mL}^{-1}$ ), rotifer growth rates increased rapidly to a maximum with increasing microalgal biomass concentration (Fig. 2A). This type of response of growth rate of a predator to the concentration of its food corresponds to a Holling type II functional response and is the result of satiation of feeding rates of the predator at high food concentrations. A Holling type II functional response can be modeled using a rectangular hyperbola ( $\mathrm{n}=50, \mathrm{R}^{2}=0.4, \mathrm{p}<0.0001$ ). The maximum rotifer growth rate $\left(r_{\max }\right)$ estimated from the data was 1.4 day $^{-1}$ while the half-saturation parameter $\left(K_{r}\right)$ corresponded to a microalgal biomass concentration of $219 \mathrm{mg} \mathrm{L}^{-1}$. A Holling type II response is commonly reported for rotifers feeding on microalgae (e.g. [20,43,44]). Some studies, however, reported a Holling type III response in which the functional response is sigmoidal or S-shaped (e.g. [45,46]). In a type III response, food intake and growth rate are very low at low food concentrations and only increase above a certain threshold. In filter feeders, a type III functional response occurs when they reduce their filtration rate when food abundance is below a minimum food concentration [46]. The microalgal concentration below which feeding stops corresponds to a microalgal biomass concentration below $10^{6}$ to $10^{7}$ cells L $^{-1}$ (e.g. $[45,46]$ ). While such a low microalgal biomass concentration may occur in natural ecosystems, they are not realistic for intensive microalgal production systems.

The maximum growth rate that was measured in our experiments $\left(1.4\right.$ day $\left.^{-1}\right)$ is in agreement with previous studies of Brachionus calyciflorus (e.g. [11]: $1.84 \mathrm{day}^{-1}$, [47]: $1.2 \mathrm{day}^{-1}$ ). Although this growth rate is lower than the maximal growth rate estimated for Chlorella in our experiments ( 2.7 day $^{-1}$, see Section 2.4), it is much higher than the realized growth rate of microalgae because microalgal growth is severely light-limited in dense microalgal cultures. Growth rates of Chlorella in our experiments ranged from 0.5 at low microalgae biomass concentration to 0.05 at high microalgae biomass concentration. This is comparable to microalgal growth rates reported in large-scale microalgal cultures, which are typically only about 0.05 to 0.25 day $^{-1}$ (e.g. [48]). Because rotifers achieve much higher growth rates than microalgae, they can outgrow microalgae and ultimately cause a crash of the culture.

When rotifers are growing at their maximum growth rate of $1.4 \mathrm{day}^{-1}$, the food intake of a single rotifer amounts to $0.9510^{-3} \mathrm{mg}$ microalgal biomass rotifer ${ }^{-1}$ day $^{-1}$. This corresponds well with previous reports of maximum food intake rates of Brachionus feeding on Chlorella (e.g. [49]: $0.97 \quad 10^{-3} \mathrm{mg}$ rotifer $^{-1}$ day $^{-1}$, [50]: 0.65 $10^{-3} \mathrm{mg} \mathrm{rotifer}^{-1} \mathrm{day}^{-1}$ ). This implies that rotifers can consume almost 5 times their own body mass per day (assuming that one rotifer has a biomass of $0.210^{-3} \mathrm{mg}_{\text {rotifer }}{ }^{-1}$ and the growth efficiency $\gamma$ of rotifers is $21 \%$ ). Given that a single Chlorella cell has a mass of $3.6 \mathrm{pg}$, this corresponds to a food intake of 184 Chlorella cells rotifer ${ }^{-1} \mathrm{~min}^{-1}$. This clearly illustrates the voracious nature of rotifers.

When the rotifer biomass concentration was high (above $60 \mathrm{mg} \mathrm{L}^{-1}$ ), the rotifer growth rate did not correlate with microalgal biomass concentration but was instead related to rotifer biomass concentration. Rotifer growth rates declined linearly with increasing rotifer biomass concentration and became negative above a rotifer biomass concentration of $184 \mathrm{mg} \mathrm{L}^{-1}$ or 920 rotifers $\mathrm{mL}^{-1}$ (Fig. 2B) $(\mathrm{n}=32$, $\mathrm{R}^{2}=0.39, \mathrm{p}=0.0001$ ). This demonstrates that rotifer populations in microalgal cultures cannot increase indefinitely but growth rates slow down and even become negative when rotifer biomass concentration in the cultures is high. This decline in rotifer growth rate at high rotifer densities was not caused by food shortages because it occurred even when microalgal food concentration was well above the saturating food concentration (e.g. Fig. 1C). The rotifer biomass concentration above which rotifer growth rates becomes negative corresponds to the carrying capacity of the rotifer population $C_{r}$ and was estimated at $184 \mathrm{mg} \mathrm{L}^{-1}$. Similar carrying capacities have been reported in studies on mass production of the rotifer Brachionus for aquaculture feed: Suantika et al. (2000) reported a maximum rotifer biomass concentration of $100-200 \mathrm{mg} \mathrm{L}^{-1}$ or $500-1000$ rotifers $\mathrm{mL}^{-1}$, similar to this study [51].

It is not clear from the literature what limits the maximum biomass concentration of rotifers or their carrying capacity. The main causes that are proposed in the literature are low oxygen levels, high levels of un-dissociated ammonia $\left(\mathrm{NH}_{3}\right)$, fluctuations in $\mathrm{pH}$ and accumulation of organic waste compounds such as rotifer feces and egg shells (e.g. [52-54]). To elucidate the causes of inhibition at high rotifer biomass concentrations, we monitored the environmental conditions in a culture that was contaminated with rotifers and compared the conditions with a control culture (Fig. 3). In the contaminated culture, a slight decrease in $\mathrm{pH}$ was observed to values below pH 7.25. Because this is well below the $\mathrm{pK}_{\mathrm{a}}$ of ammonia ( $\mathrm{pH}$ 9.25), it is unlikely that un-associated ammonia would have accumulated to toxic levels. Dissolved oxygen concentrations dropped to very low values in a Chlorella culture that was contaminated with Brachionus when rotifer biomass in the culture exceeded $100 \mathrm{mg} \mathrm{L}^{-1}$. Despite the fact that the cultures were continuously aerated, dissolved oxygen concentrations often approached 0 at night and were low even during the day, when microalgal photosynthesis generates oxygen (Fig. 3). This oxygen depletion is most likely due to respiration of oxygen by the rotifers. Although rotifers are quite tolerant to low oxygen levels, they cannot tolerate oxygen concentrations 


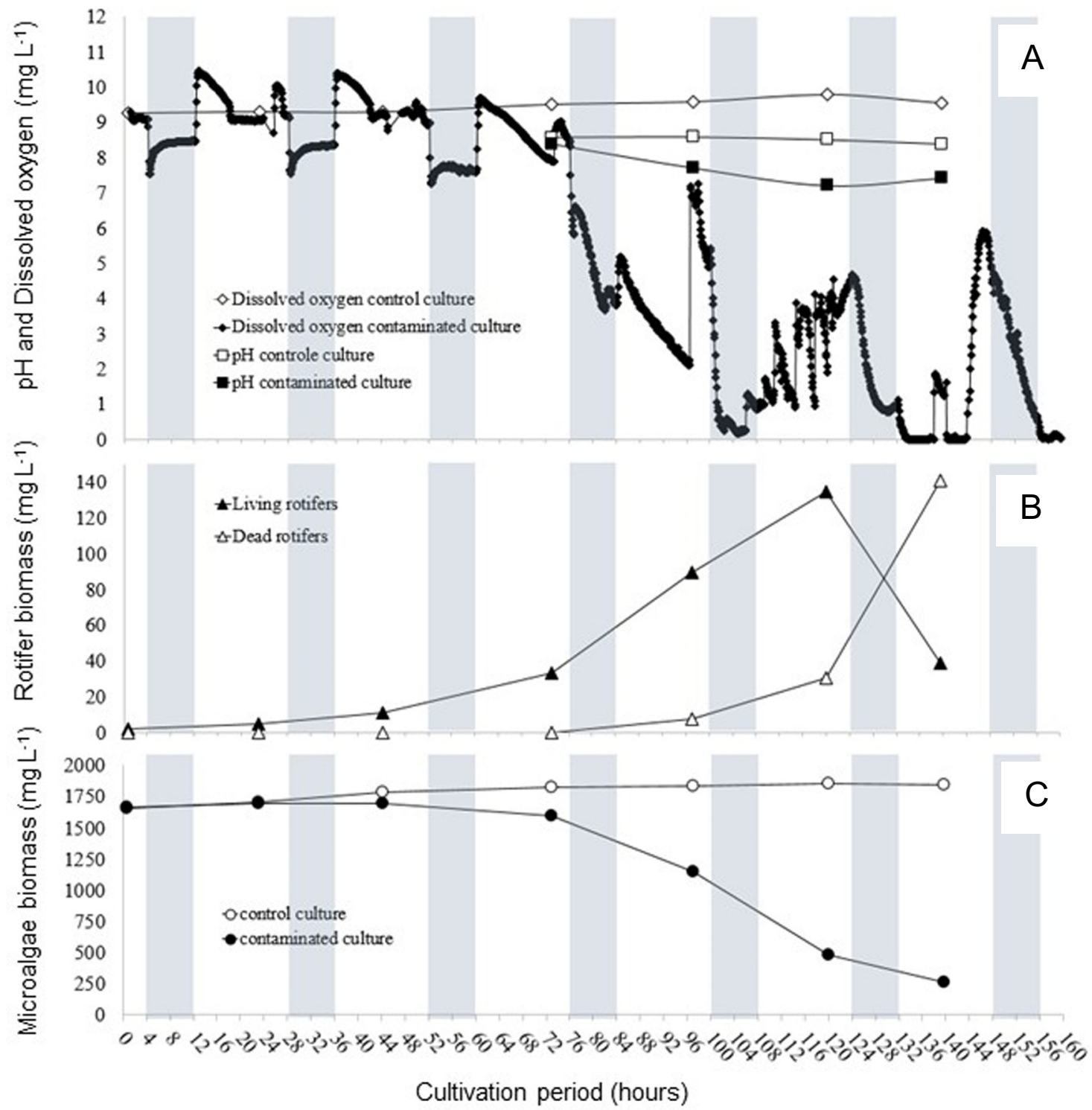

Fig. 3. (A) Evolution of $\mathrm{pH}$ and dissolved oxygen concentration $\left(\mathrm{mg} \mathrm{L}^{-1}\right)$ in a Brachionus contaminated and control Chlorella culture over a 7-day cultivation period. Dissolved oxygen concentration was monitored with a fluorescent dissolved oxygen probe (DO; HQ40D, HACH, USA) at high resolution (5 min interval). (B) Living and dead rotifers ( $\left.\mathrm{mg} \mathrm{L}^{-1}\right)$ during cultivation. (C) Microalgae biomass $\left(\mathrm{mg} \mathrm{L}^{-1}\right)$ change in the contaminated and control culture. Alternate bright and shaded areas indicate the $16-8 \mathrm{~h}$ light-dark regime during cultivation.

below $2 \mathrm{mg} \mathrm{L}^{-1}$ [52]. Therefore, we hypothesize that the carrying capacity of the rotifer population is regulated by the oxygen consumption by the rotifers. The maximum biomass concentration that can be achieved by rotifers in turn limits the rate of microalgal biomass consumption by these rotifers. Given a carrying capacity of 920 rotifers $\mathrm{mL}^{-1}$ and a maximum food intake of $0.9510^{-3}$ mgrotifer $^{-1}$ day $^{-1}$, the maximum daily consumption of microalgal biomass by rotifers can be estimated to be around $874 \mathrm{mg}$ microalgal biomass $\mathrm{L}^{-1}$ day $^{-1}$.

The data from the laboratory experiments were used to develop a model that describes microalgal and rotifer growth rates. This model was then applied to the starting conditions of each of the experimental treatments (Supplementary Information Fig. S4). The modeled response of rotifer and microalgal biomass fitted quite well with the observed response in the experiments. This indicates that the model is capable of accurately reproducing the dynamics of rotifers and microalgae in the experimental treatments.
3.2. Modeling of impact of rotifer contamination on microalgae production in three types of cultivation systems

The model that was developed to simulate population dynamics of rotifers and microalgae in the laboratory experiments was subsequently applied to simulate the impact of rotifer contamination on microalgal biomass production in three types of large-scale microalgae cultivation systems: an open raceway pond (ORP), a horizontal flat-panel photobioreactor (HFP) and a thin layer cascade (TLC). These three systems differ in the operational biomass concentration: $0.5 \mathrm{gL}^{-1}$ in the ORP, $4 \mathrm{~g} \mathrm{~L}^{-1}$ in the HFP and $30 \mathrm{~g} \mathrm{~L}^{-1}$ in the TLC (e.g. $\left.[55,56]\right)$. The modeled growth rate of the microalgae in these systems at this operational biomass concentration was comparable: 0.15 day $^{-1}$ for the ORP, 0.11 day $^{-1}$ for the HFP and 0.13 day $^{-1}$ for the TLC system. The systems were assumed to be operated in continuous growth mode and the dilution rate was set at the growth rate of the microalgae, resulting in a constant microalgal biomass concentration in the absence of rotifer contamination. The modeled areal productivity in continuous mode was comparable in the three systems and was $22.4 \mathrm{~g} \mathrm{~m}^{-2}$ day $^{-1}$ in the 


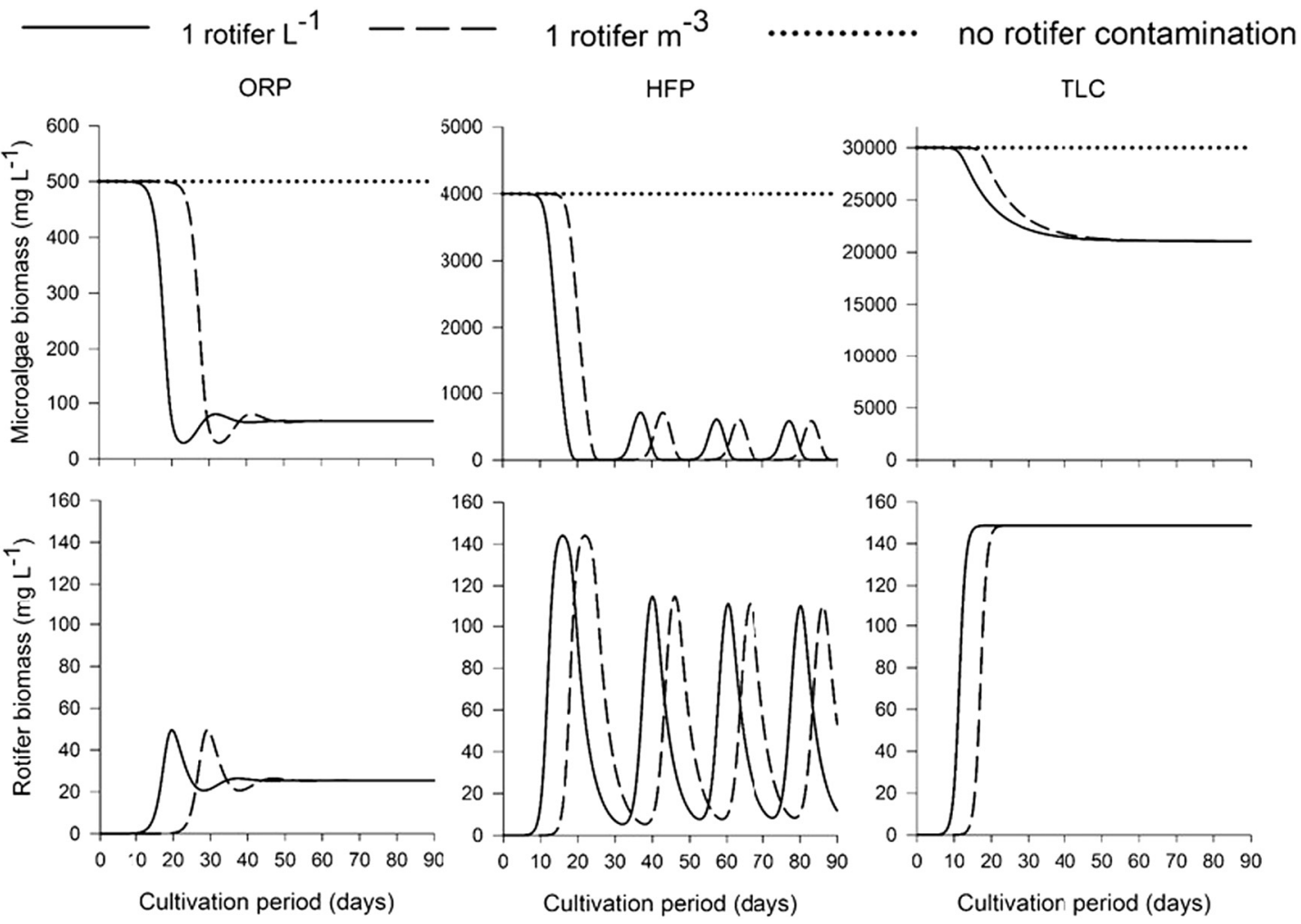

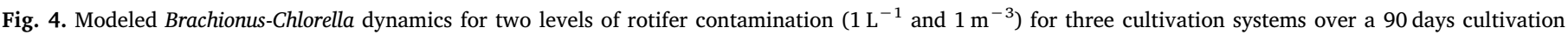

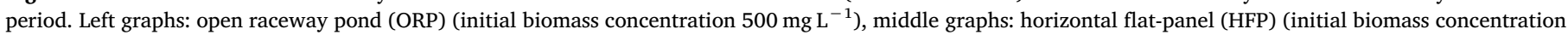

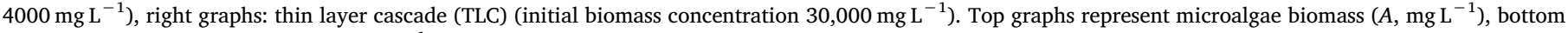
graphs represent rotifer biomass $\left(R, \mathrm{mg} \mathrm{L}^{-1}\right)$. Note the different $\mathrm{y}$-axis scale for microalgae biomass.

ORP, $22.8 \mathrm{~g} \mathrm{~m}^{-2}$ day $^{-1}$ in the HFP to $22.6 \mathrm{~g} \mathrm{~m}^{-2}$ day $^{-1}$ in the TLC system. These values are similar to productivities reported for real-life systems: typical daily areal productivities for various microalgae species vary from 6.2 to $27 \mathrm{~g} \mathrm{~m}^{-2}$ day $^{-1}$ in open pond systems (e.g. $[48,57,58]$ ), 20 to $30 \mathrm{~g} \mathrm{~m}^{-2}$ day $^{-1}$ in enclosed photobioreactors (e.g. tubular, column or flat plate) [57] and 22 to $25 \mathrm{~g} \mathrm{~m}^{-2}$ day $^{-1}$ in thin layer cascade systems (e.g. [55,59-61]). This indicates that our model is capable of simulating microalgal productivity in the three different cultivation systems.

The impact of rotifer contamination on the microalgal biomass concentration in these three systems was modeled for two levels of rotifer contamination (initiation rotifer abundance $1 \mathrm{~L}^{-1}$ and $1 \mathrm{~m}^{-3}$; Fig. 4). The impact of rotifer contamination and the predator-prey dynamics differed strongly between the three cultivation systems. The two levels of initial rotifer abundance resulted in a similar impact on microalgal biomass concentration in the different systems, but the timing of the impact was delayed by about 10 days in the ORP and 5 days in the HFP and TLC systems when initial rotifer abundance was decreased from $1 \mathrm{~L}^{-1}$ to $1 \mathrm{~m}^{-3}$.

In what follows the dynamics for the highest level of rotifer contamination $\left(1 \mathrm{~L}^{-1}\right)$ for each system are discussed in detail. In the ORP system, the microalgal biomass concentration was relatively low, below the half-saturation constant for rotifer growth rates $\left(K_{r}\right)$. As a result, the rotifer growth rate was lower than in the other systems and it took 20 days for the rotifer population to reach its maximum. This increase in rotifer biomass was associated with a decline in microalgal biomass. After a peak in rotifer biomass and decline in microalgal biomass, rotifer biomass declined again slightly and microalgal biomass increased slightly to reach a steady state condition. In this steady state condition, microalgal biomass concentration was $94.4 \%$ lower than in a noncontaminated culture. In the HFP system, the microalgal biomass concentration was well above $K_{r}$ and, therefore, the rotifer growth rate was higher and rotifer biomass reached a peak after 15 days. This peak in rotifer biomass was followed by a massive decline in microalgal biomass to only $1 \mathrm{mg} \mathrm{L}^{-1}$. The decline in microalgal biomass concentration was followed by a steep decline in the rotifer population. Afterwards, microalgal biomass increased again and this increase was again followed by an increase in rotifer biomass. This cycle of increases and decreases in rotifer and microalgal biomass concentration was repeated. On average, microalgal biomass concentration in this system was $96.7 \%$ lower compared to a non-contaminated culture. In the TLC system, microalgal biomass concentration was also well above the $K_{r}$ and rotifer biomass increased to a maximum of $149 \mathrm{mg} \mathrm{L}^{-1}$ after 15 days. As rotifer biomass reached its maximum, microalgal biomass decreased slowly to $21 \mathrm{~g} \mathrm{~L}^{-1}$ after approximately 45 days. This is about $29.8 \%$ lower than in the non-contaminated culture. In this system, microalgal biomass concentration never dropped below the level that might limit rotifer growth rates and the rotifer population was constantly near its carrying capacity.

This modeling exercise suggests that rotifer can cause an almost complete loss of biomass of the culture in ORP and HFP systems, while losses are much smaller in a TLC system. In the TLC system, the final rotifer biomass concentration $\left(149 \mathrm{mg} \mathrm{L}^{-1}\right)$ is limited by the carrying capacity and the dilution rate of the system. The maximum consumption of the rotifer population at its maximum growth rate ( $874 \mathrm{mg} \mathrm{L}^{-1}$ day $^{-1}$ ) is lower than the volumetric biomass productivity of the system, which is extremely high $\left(3770 \mathrm{mg} \mathrm{L}^{-1} \mathrm{day}^{-1}\right)$, and this prevents a complete crash of the culture. This model only evaluates the impact of contamination, not the risk of contamination. It is obvious that closed photobioreactors have a lower risk of contamination than open ponds and thin layer cascade systems because the latter are open to the atmosphere. Nevertheless, even in closed photobioreactors contamination is hard to avoid because of the large specific surface area of the reactors which makes complete sterilization difficult [57]. 
Moreover, large quantities of water are needed to prepare the culture medium and the cultures are sparged with large volumes of air, both of which are hard to completely sterilize [62].

According to our model, all three systems evolve to a state where microalgae and rotifers coexist. The ORP and TLC evolve to a stable equilibrium and the HFP evolves to a stable limit cycle. In a classical Lotka-Volterra predator-prey system, populations of prey and predator tend to vary cyclically [42]. These cycles can be dampened when growth of prey and predator are regulated by self-limitation (as is the case for both microalgae and rotifers in our model) and can be magnified by increases in productivity of the prey population (as is the case for the volumetric productivity of the microalgae). The properties of the models can be visualized by zero isoclines in the prey and predator space (Supplementary Information Fig. S3). The shift from a stable equilibrium in the ORP system to continuing limit cycles in the HFP can be ascribed to an increase in volumetric productivity of the microalgae. This is known in theoretical population biology as the "paradox of enrichment' [63]. A Brachionus-Chlorella chemostat experiment performed by Fussmann et al. (2000) confirmed that an increase in productivity indeed causes enhanced predator-prey cycles [44]. A further increase in microalgal volumetric productivity from the HFP to the TLC system shifts the dynamics back to a stable equilibrium. This is mainly the result of the fact that the rotifer population reaches its carrying capacity [42]. The limited ability of the rotifer population near its carrying capacity to impact the microalgal biomass concentration stabilizes this system.

In this study, the modeling of rotifer growth rates was only dependent on microalgal biomass concentration and rotifer density. It is important to note that the predicted microalgae-rotifer dynamics of the simple model developed in this study can be influenced by a multitude of biological mechanisms and therefore be improved. For instance, in our model, biomass of an individual rotifer was assumed to be constant. Nevertheless, it is known that the biomass may differ up to $100 \%$ between egg-bearing and non-egg-bearing females (e.g. [33]). The number of egg-bearing females and the number of eggs per female is known to be variable according to the population density and culture conditions (e.g. food concentration and temperature) [64]. During the course of our experiments, we observed changes in the relative abundance of egg-bearing females and in the number of eggs per female (Supplementary information Fig. S5). The number of egg-bearing females varied from 10 to $36 \%$ and the average number of eggs per eggbearing female varied from 1 to 2.2 , but with a large pooled variance of 0.77 . Despite the fact that these differences in the population structure were not taken into account, our model was capable of reproducing the observed rotifer population dynamics in our experiments fairly accurately. Many other published rotifer population models also assume a fixed biomass per individual, as in our model (e.g. [17,44,65]). Some studies, however, differentiate between rotifers with and without eggs, or even between eggs, juveniles and adults (e.g. [66,67]). Future models may be improved by taking into account these different subpopulations.

Also the growth of the microalgal species can be indirectly influenced by the presence of a predator. The microalgal species might respond to the predator by developing a defense mechanism such as a thicker cell wall, colony formation or development of spines which would reduce the grazing impact of the predator and therefore losses of microalgal productivity. Such predator-induced defense mechanisms have been reported in commercially important microalgae strains, such as some Chlorella strains ([50]; thicker cell wall) or in Scenedesmus strains ([68]; colony formation and/or spine development). Because such predator-induced responses are constitutively expressed they are likely to come at a cost [68]. This might result in a reduction of microalgal growth rates and therefore a reduction in the biomass productivity of the culture. Also, changes in food quality resulting from alterations in the quantity or ratio of nutrients in the culture medium may influence rotifer population dynamics [12]. For instance, Flynn et al. [69] modeled the influence of varying microalgal C/N/P ratios on the invasion success of predators and the resulting predator-prey dynamics in intensive microalgae production cultures [69]. Cultures with microalgae having low N/C and/or P/C ratios reduced predator growth and experienced less biomass losses.

\section{Conclusions}

Based on controlled laboratory contamination experiments a rotifermicroalgae dynamics model was developed. The rotifer model was coupled to a model describing primary production in three types of large-scale cultivation systems. The results suggest that open raceway ponds and closed photobioreactors with operational biomass concentrations of 0.5 to $5 \mathrm{~g} \mathrm{~L}^{-1}$ will suffer large losses in productivity from rotifer predation (>90\%). Thin layer cascade systems which have extremely high operational biomass concentration suffer lower losses $(<30 \%)$, mainly because rotifers cannot achieve a sufficiently high biomass to impact the high rates of volumetric biomass productivity of these systems.

\section{Acknowledgements}

This research was financially supported by the Research Foundation Flanders (FWO Ph.D. Fellowship B. Deruyck). Nguyen Thi Kim Hue was supported by a PhD scholarship provided by the Ministry of Education and Training of Vietnam. We are grateful to Andries Vansweevelt for his efforts on the numerical simulations for the predator-prey isoclines.

All the authors declare that there are no conflicts of interest.

No informed consent or human or animal rights are applicable.

\section{Declaration of author's contributions}

We confirm that the order of authors listed in the manuscript and author's contributions below has been approved by all authors. We confirm that Mr. Bert Deruyck is the corresponding author who has taken responsibility for the integrity of the work as a whole, from inception to finished article. We confirm the contributions of authors as the following:

\begin{tabular}{llll}
\hline Order & Name & Email address & Contributions \\
\hline 1 & Bert Deruyck & bert.deruyck@kuleuven.be & $(1)$ \\
2 & Nguyen Thi Kim Hue & thikimhue.nguyen@kuleuven.be & $(2)$ \\
3 & Ellen Decaestecker & ellen.decaestecker@kuleuven.be & $(2)$ \\
4 & Koenraad Muylaert & koenraad.muylaert@kuleuven.be & $(3)$ \\
\hline
\end{tabular}

(1) Conception and design, provision of study materials, collection and assembly of data, analysis and interpretation of the data, statistical expertise, drafting of the article, critical revision of the article for important intellectual content, final approval of the article.

(2) Statistical expertise, critical revision of the article for important intellectual content, final approval of the article.

(3) Obtaining of funding; conception and design; statistical expertise; administrative, technical, or logistic support; drafting of the article; critical revision of the article for important intellectual content; final approval of the article.

\section{Appendix A. Supplementary data}

Supplementary data to this article can be found online at https:// doi.org/10.1016/j.algal.2018.101398.

\section{References}

[1] T.M. Mata, A.a. Martins, N.S. Caetano, Microalgae for biodiesel production and other applications: a review, Renew. Sust. Energ. Rev. 14 (2010) 217-232, https:// 
doi.org/10.1016/j.rser.2009.07.020

2] D.R. Georgianna, S.P. Mayfield, Exploiting diversity and synthetic biology for the production of algal biofuels, Nature 488 (2012) 329-335, https://doi.org/10.1038/ nature11479.

[3] J.W. Richardson, M.D. Johnson, X. Zhang, P. Zemke, W. Chen, Q. Hu, A financial assessment of two alternative cultivation systems and their contributions to algae biofuel economic viability, Algal Res. 4 (2014) 96-104, https://doi.org/10.1016/j algal.2013.12.003.

[4] R.C. McBride, V.H. Smith, L.T. Carney, T.W. Lane, Crop protection in open ponds, in: S.P. Slocombe, J.R. Benemann (Eds.), Microalgal Prod. Biomass High-Value Prod, 1st ed., CRC Press, 2016, pp. 165-182.

[5] V. Montemezzani, I.C. Duggan, I.D. Hogg, R.J. Craggs, A review of potential methods for zooplankton control in wastewater treatment High Rate Algal Ponds and algal production raceways, Algal Res. 11 (2015) 211-226, https://doi.org/10 1016/j.algal.2015.06.024.

[6] I. Moreno-Garrido, J.P. Cañavate, Assessing chemical compounds for controlling predator ciliates in outdoor mass cultures of the green algae Dunaliella salina, Aquac. Eng. 24 (2001) 107-114, https://doi.org/10.1016/S0144-8609(00) 00067-4.

[7] V. Montemezzani, I.C. Duggan, I.D. Hogg, R.J. Craggs, Zooplankton community influence on seasonal performance and microalgal dominance in wastewater treatment High Rate Algal Ponds, Algal Res. 17 (2016) 168-184, https://doi.org/ 10.1016/j.algal.2016.04.014.

[8] J.G. Day, Grazers: the overlooked threat to the sustained production of future algal biofuels, Biofuels 4 (2013) 459-461, https://doi.org/10.4155/bfs.13.29.

[9] L.T. Carney, J.S. Wilkenfeld, P.D. Lane, O.D. Solberg, Z.B. Fuqua, N.G. Cornelius, S. Gillespie, K.P. Williams, T.M. Samocha, T.W. Lane, Pond crash forensics: presumptive identification of pond crash agents by next generation sequencing in replicate raceway mass cultures of Nannochloropsis salina, Algal Res. 17 (2016) 341-347, https://doi.org/10.1016/j.algal.2016.05.011.

[10] D. Yuan, X. Zhan, M. Wang, X. Wang, W. Feng, Y. Gong, Q. Hu, Biodiversity and distribution of microzooplankton in Spirulina (Arthrospira) platensis mass culture throughout China, Algal Res. 30 (2018) 38-49, https://doi.org/10.1016/j.algal. 2017.12.009.

[11] W.N. Bennett, M.E. Boraas, A demographic profile of the fastest growing metazoan a strain of Brachionus calyciflorus (Rotifera), Oikos 55 (1989) 365.

[12] S.a.J. Declerck, A.R. Malo, S. Diehl, D. Waasdorp, K.D. Lemmen, K. Proios, S. Papakostas, Rapid adaptation of herbivore consumers to nutrient limitation: ecoevolutionary feedbacks to population demography and resource control, Ecol. Lett. (2015), https://doi.org/10.1111/ele.12436 (n/a-n/a).

[13] R.L. Wallace, H.A. Smith, Rotifera, ELS (2013) 1-8, https://doi.org/10.1002/ 9780470015902.a0001588.pub2.

[14] R. Wallace, T.W. Snell, Rotifera, in: J. Thorp, A. Covich (Eds.), Ecol. Classif. North Am. Fresh- Water Invertebr, 3rd ed., Amsterdam Elsevier, Inc., Oxfod, 2010, pp. $173-235$.

[15] N. Walz, Rotifer populations in plankton communities: energetics and life history strategies, Experientia 51 (1995) 437-453, https://doi.org/10.1007/BF02143197.

[16] A. Herzig, The analysis of planktonic rotifer populations: a plea for long-term investigations, Hydrobiologia 147 (1987) 163-180, https://doi.org/10.1007/ BF00025739.

[17] T. Yoshida, L.E. Jones, S.P. Ellner, G.F. Fussmann, N.G. Hairston, Rapid evolution drives ecological dynamics in a predator-prey system, Nature 424 (2003) 303-306, https://doi.org/10.1038/nature01767.

[18] S. Nandini, S.S.S. Sarma, R.J. Amador-López, S. Bolaños-Muñioz, Population growth and body size in five rotifer species in response to variable food concentration, J. Freshw. Ecol. 22 (2007) 1-10, https://doi.org/10.1080/02705060.2007.9664139.

[19] H.I. Forehead, C.J. O'Kelly, Small doses, big troubles: modeling growth dynamics of organisms affecting microalgal production cultures in closed photobioreactors, Bioresour. Technol. 129 (2013) 329-334, https://doi.org/10.1016/j.biortech.2012. 11.082.

[20] K.O. Rothhaupt, Changes of the functional responses of the rotifer Brachionus rubens and Brachionus calyciflorus with particle sizes, Limnol. Oceanogr. 35 (1990) 24-32.

[21] N.R. Moheimani, D. Parlevliet, M.P. McHenry, P.A. Bahri, K. de Boer, Past, present and future of microalgae cultivation developments, in: N.R. Moheimani, M.P. McHenry, P.A. Bahri, K. de Boer (Eds.), Biomass Biofules Form Microalgae, 1st ed., Springer International Publishing, Switzerland, 2015, pp. 1-18.

[22] C.P. Stelzer, Population regulation in sexual and asexual rotifers: an eco-evolutionary feedback to population size? Funct. Ecol. 26 (2012) 180-188, https://doi. org/10.1111/j.1365-2435.2011.01918.x.

[23] S.W. Van Ginkel, T. Igou, Z. Hu, A. Narode, S. Cheruvu, S. Doi, R. Johnston, T. Snell, Y. Chen, Taking advantage of rotifer sensitivity to rotenone to prevent pond crashes for algal-biofuel production, Algal Res. 10 (2015) 100-103, https://doi.org/10. 1016/j.algal.2015.03.013.

[24] P.K. Thomas, G.P. Dunn, M. Passero, K.P. Feris, Free ammonia offers algal crop protection from predators in dairy wastewater and ammonium-rich media, Bioresour. Technol. 243 (2017) 724-730, https://doi.org/10.1016/j.biortech.2017. 07.008

[25] Y. Huang, L. Li, J. Liu, W. Lin, Botanical pesticides as potential rotifer-control agents in microalgal mass culture, Algal Res. 4 (2014) 62-69, https://doi.org/10 1016/j.algal.2013.08.001.

[26] V. Montemezzani, I.C. Duggan, I.D. Hogg, R.J. Craggs, Control of zooplankton populations in a wastewater treatment High Rate Algal Pond using overnight $\mathrm{CO} 2$ asphyxiation, Algal Res. 26 (2017) 250-264, https://doi.org/10.1016/j.algal.2017. 08.004

[27] M.A. Borowitzka, Culturing microalgae in outdoor ponds, in: R.A. Anderson (Ed.), Algal Cult. Tech, Academc Press, New York, 2005, pp. 205-2017.
[28] D. Kim, E.K. Kim, H.G. Koh, K. Kim, J.I. Han, Y.K. Chang, Selective removal of rotifers in microalgae cultivation using hydrodynamic cavitation, Algal Res. 28 (2017) 24-29, https://doi.org/10.1016/j.algal.2017.09.026.

[29] J.G. Day, Y. Gong, Q. Hu, Microzooplanktonic grazers - a potentially devastating threat to the commercial success of microalgal mass culture, Algal Res. 27 (2017) 356-365, https://doi.org/10.1016/j.algal.2017.08.024.

[30] L. Christenson, R. Sims, Production and harvesting of microalgae for wastewater treatment, biofuels, and bioproducts, Biotechnol. Adv. 29 (2011) 686-702, https:// doi.org/10.1016/j.biotechadv.2011.05.015.

[31] N.H. Norsker, M.J. Barbosa, M.H. Vermuë, R.H. Wijffels, Microalgal production - a close look at the economics, Biotechnol. Adv. 29 (2011) 24-27, https://doi.org/10. 1016/j.biotechadv.2010.08.005.

[32] R.R.L. Guillard, C.J. Lorenzen, Yellow-green algae with chlorophyllide C12, J. Phycol. 8 (1972) 10-14.

[33] H.J. Dumont, I. Van de Velde, S. Dumont, The dry weight estimate of biomass in a selection of Cladocera, Copepoda and Rotifera from the plankton, periphyton and benthos of continental waters, Oecologia 19 (1975) 75-97, https://doi.org/10. 1007/BF00377592.

[34] R.S. Stemberger, J.J. Gilbert, Body size, food concentration, and population growth in planktonic rotifers, Ecology 66 (1985) 1151-1159.

[35] J. Huismann, F.J. Weissing, Light-limited growth and competition for light in wellmixed aquatic environments: an elementary model author (s): Jef Huisman and Franz J. Weissing published by: Wiley on behalf of the ecological Society of America Stable URL: http://www.jstor.org/, Ecology 75 (1994) 507-520, https://doi.org/ 10.2307/1939554.

[36] M.H. Huesemann, J. Van Wagenen, T. Miller, A. Chavis, S. Hobbs, B. Crowe, A screening model to predict microalgae biomass growth in photobioreactors and raceway ponds, Biotechnol. Bioeng. 110 (2013) 1583-1594, https://doi.org/10. 1002/bit.24814.

[37] R.J. Ritchie, Fitting light saturation curves measured using modulated fluorometry, Photosynth. Res. 96 (2008) 201-215, https://doi.org/10.1007/s11120-008-9300-7.

[38] P.M.J. Herman, K. Soetaert, Model Formulation, P.M.J. Herman, K. Soetaert (Eds.), A practical guide to ecological modelling, first edition, Springer, Netherlands, 2009, pp. 15-70.

[39] R.J. Geider, H.L. MacIntyre, T.M. Kana, A dynamic regulartory model of photoplankton acclimation to light, nutrients and temperature, Limnol. Oceanogr. 43 (1998) 679-694.

[40] W. Blanken, P.R. Postma, L. de Winter, R.H. Wijffels, M. Janssen, Predicting microalgae growth, Algal Res. 14 (2016) 28-38, https://doi.org/10.1016/j.algal 2015.12.020.

[41] P. Funch, H. Segers, H.J. Dumont, Rotifera in tap water in Gent, Belgium, Biol. Jaarb Dodonaea. 63 (1996) 53-57.

[42] M. Begon, J.L. Harper, C.R. Townsend, The population dynamics of predation, in: M. Begon, J.L. Harper, C.R. Townsend (Eds.), Ecology, third, Blackwell Science Ltd, Malden, 1996, pp. 369-401.

[43] A.B. Felpeto, N.G. Hairston, Indirect Bottom-Up Control of Consumer - Resource Dynamics: Resource-Driven Algal Quality Alters Grazer Numerical Response, 58 (2013), pp. 827-838, https://doi.org/10.4319/1o.2013.58.3.0827.

[44] G.F. Fussmann, S.P. Ellner, K.W. Shertzer, N.G. Hairston, Crossing the Hopf bifurcation in a life predator-prey system, Science 290 (2000) 1358-1360 (80-. ).

[45] C. Alves-de-Souza, D. Pecqueur, E. Le Floc'H, S. Mas, C. Roques, B. Mostajir, F. Vidussi, L. Velo-Suárez, M. Sourisseau, E. Fouilland, L. Guillou, Significance of plankton community structure and nutrient availability for the control of dinoflagellate blooms by parasites: a modeling approach, PLoS One 10 (2015) 1-15, https://doi.org/10.1371/journal.pone.0127623.

[46] G.F. Fussmann, G. Weithoff, T. Yoshida, A. Direct, Experimental test of resource vs. consumer dependence, Ecology 86 (2007) 2924-2930.

[47] Y.-L. Xi, G.-Y. Liu, H.-J. Jin, Population growth, body size, and egg size of two different strains of Brachionus calyciflorus Pallas (Rotifera) fed different algae, J. Freshw. Ecol. 17 (2002) 185-190, https://doi.org/10.1080/02705060.2002. 9663886.

[48] J.H. de Vree, R. Bosma, M. Janssen, M.J. Barbosa, R.H. Wijffels, Comparison of four outdoor pilot-scale photobioreactors, Biotechnol. Biofuels. 8 (2015) 215, , https:// doi.org/10.1186/s13068-015-0400-2.

[49] N.H. George, Growth, filtration and ingestion rate of the rotifer Brachionus plicatilis fed with large (Asteromonas gracilis) and small (Chlorella sp.) celled algal species, Aquac. Res. 34 (2003) 793-802, https://doi.org/10.1046/j.1365-2109.2003 00868.x.

[50] T. Yoshida, N.G. Hairston, S.P. Ellner, Evolutionary trade-off between defence against grazing and competitive ability in a simple unicellular alga, Chlorella vulgaris, Proc. Biol. Sci. 271 (2004) 1947-1953, https://doi.org/10.1098/rspb.2004. 2818.

[51] G. Suantika, P. Dhert, M. Nurhudah, P. Sorgeloos, High-density production of the rotifers brachionus plicatilis in a recirculation system; consideration of water quality, zoutechnical and nutritional aspect, Aquac. Eng. 21 (2000) 201-214.

[52] H.G. Park, K.W. Lee, S.H. Cho, H.S. Kim, M.M. Jung, H.S. Kim, High density culture of the freshwater rotifer, Brachionus calyciflorus, Hydrobiologia 446-447 (2001) 369-374, https://doi.org/10.1023/A:1017571327829.

[53] T. Yoshimatsu, M.A. Hossain, Recent advances in the high-density rotifer culture in Japan, Aquac. Int. (2014), https://doi.org/10.1007/s10499-014-9767-5.

[54] T. Yoshinaga, A. Hagiwara, K. Tsukamoto, Why do rotifer populations present a typical sigmoid growth curve? Hydrobiologia 446-447 (2001) 99-105, https://doi. org/10.1023/A:1017510220444.

[55] J. Doucha, K. Lívanský, Productivity, CO2/O2exchange and hydraulics in outdoor open high density microalgal (Chlorella sp.) photobioreactors operated in a middle and southern European climate, J. Appl. Phycol. 18 (2006) 811-826, https://doi. 
org $/ 10.1007 /$ s10811-006-9100-4

[56] G.C. Zittelli, B.N. Rodolfi, M.R. Tredicid, Photobioreactors for mass production of microalgae, in: A. Richmond, Q. Hu (Eds.), Handb. Microalgal Mass Cult. Appl. Phycol. Biotechnol, Blackwell Science Ltd, Chichester, 2013, pp. 225-266.

[57] Y.K. Lee, Microalgal mass culture systems and methods: their limitation and potential, J. Appl. Phycol. 13 (2001) 307-315, https://doi.org/10.1023/ A:1017560006941.

[58] A. San Pedro, C.V. González-López, F.G. Acién, E. Molina-Grima, Outdoor pilot production of Nannochloropsis gaditana: influence of culture parameters and lipid production rates in raceway ponds, Algal Res. 18 (2015) 205-213, https://doi.org/ 10.1016/j.algal.2015.02.013.

[59] J. Doucha, K. Livansky, High density outdoor microalgal culture, in: R.K. Bajpai, A. Prokop, M.E. Zappi (Eds.), Algal Biorefineries Vol. 1 Cultiv. Cells Prod, 1st ed., Springer, Netherlands, 2014, pp. 147-173.

[60] J. Masojídek, M. Sergejevova, J.R. Malapascua, J. Kopecký, Thin-layer systems for mass cultivation of microalgae: Flat panels and sloping cascades, in: R.K. Bajpai, A. Prokop, M.E. Zappi (Eds.), Algal Biorefineries, 1st ed., Vol. 2 Prod. Refin. Des Springer International Publishing, 2015, pp. 237-261.

[61] J. Masojídek, J. Kopecký, L. Giannelli, G. Torzillo, Productivity correlated to photobiochemical performance of Chlorella mass cultures grown outdoors in thin-layer cascades, J. Ind. Microbiol. Biotechnol. 38 (2011) 307-317, https://doi.org/10. 1007/s10295-010-0774-x.
[62] H. Wang, W. Zhang, L. Chen, J. Wang, T. Liu, The contamination and control of biological pollutants in mass cultivation of microalgae, Bioresour. Technol. 128 (2013) 745-750, https://doi.org/10.1016/j.biortech.2012.10.158.

[63] M.L. Rosenzweig, Paradox of enrichment: destabilization of exploitation ecosystem in ecological time, Science 171 (1971) 385-387, https://doi.org/10.1126/science. 171.3969.385 (80-. )

[64] S.S.S. Sarma, R.D. Gulati, S. Nandini, Factors affecting egg-ratio in planktonic rotifers, Hydrobiologia 546 (2005) 361-373, https://doi.org/10.1007/s10750-005 4247-6.

[65] K.W. Shertzer, S.P. Ellner, G.F. Fussmann, N.G. Hairston, Predator-prey cycles in an aquatic microcosm: testing hypotheses of mechanism, J. Anim. Ecol. 71 (2002) 802-815, https://doi.org/10.1046/j.1365-2656.2002.00645.x.

[66] M.E. Boraas, Population-dynamics of food-limited rotifers in 2-stage chemostat culture, Limnol. Oceanogr. 28 (1983) 546-563.

[67] J.N. McNair, M.E. Boraas, D.B. Seale, Size-structure dynamics of the rotifer chemostat: a simple physiologically structured model, Hydrobiologia 387 (388) (1998) 469-476.

[68] M. Lurling, E. Van Donk, Grazer-induced colony formation in Scenedesmus: are there costs to being colonial? Oikos 88 (2000) 111-118, https://doi.org/10.1034/j.1600 0706.2000.880113.x.

[69] K.J. Flynn, P. Kenny, A. Mitra, Minimising losses to predation during microalgae cultivation, J. Appl. Phycol. (2017), https://doi.org/10.1007/s10811-017-1112-8. 